\title{
An IoT based Control System for a Solar Membrane Distillation Plant used for Greenhouse Irrigation*
}

\author{
Juan D. Gil \\ Centro Mixto CIESOL, ceiA3 \\ Universidad de Almería \\ Ctra. Sacramento s/n, Almería 04120, Spain \\ juandiego.gil@ual.es \\ Francisco Rodríguez \\ Centro Mixto CIESOL, ceiA3 \\ Universidad de Almería \\ Ctra. Sacramento s/n, Almería 04120, Spain \\ frrodrig@ual.es
}

\author{
Manuel Muñoz \\ Centro Mixto CIESOL, ceiA3 \\ Universidad de Almería
}

Ctra. Sacramento s/n, Almería 04120, Spain

mmr411@ual.es

\author{
Lidia Roca \\ Ctra. de Senés s/n,Tabernas \\ 04200, Almería, Spain \\ lidia.roca@psa.es
}

\begin{abstract}
This paper presents a control strategy that uses the Internet of Things (IoT) technology to manage a smart-grid framework including a solar desalination facility and a group of greenhouses that demand water for irrigation. In addition, the water public utility network has also been considered an agent of this smart-grid framework. The controller is based on a Model Predictive Control (MPC) strategy which uses information, by means of an IoT platform, coming from each one of the facilities included in the smart-grid to calculate the optimal control actions in the Cloud. Simulation results are shown to demonstrate the efficiency of the proposed method.
\end{abstract}

Index Terms-Model Predictive Control; Solar Energy; Desalination; Smart Management; Cloud Computing.

\section{INTRODUCTION}

Agriculture plays a major role in the economy of most cities of the Mediterranean area. This is the case of Almería (Southeast of Spain), which is located in a semi-desertic region with a serious problem of water shortage. However, despite this problem, the agriculture system in Almería increases steadily, and nowadays, it is composed by more than 31034 greenhouse hectares [6]. The development of such an intensive agriculture system in this dry zone demands solutions for its sustainability. In this sense, as pointed by [3], the combination of desalination processes with crops could become one of the main tools to alleviate the water problem. Nevertheless, some drawbacks must be faced before, among which, the associated economics costs stand out.

One way to decrease the costs of the freshwater produced by means of desalination processes is to combine them with renewable energies. In this way, Membrane Distillation (MD) technology is a thermal separation process with potential in

This work has been funded by IoF2020 Horizon 2020 Framework Programme of the European Union - Grant Agreement no. 731884 - and by the Spanish R+D+i Plan Project DPI2017-85007-R of the Ministry of Economy, Industry and Competitiveness and ERDF funds.

978-1-7281-2171-0/19/\$31.00 @ 2019 IEEE comparison to other desalination technologies, since it requires a low operational temperature, what makes that it can be easily coupled with solar thermal energy [20]. Although this technology is currently more expensive than other desalination processes, i.e. reverse osmosis, it is adequate to develop smallmedium desalination applications to be implanted in places with good solar irradiance conditions and access to sea water, as happens in Almería.

Towards sustainable irrigated crops, the connection of greenhouses and Solar Membrane Distillation (SMD) facilities should be performed by using adequate control systems, in which the Internet of Things (IoT) framework is becoming an enabling technology. On the one hand, bearing in mind a thermal desalination plant powered with solar thermal energy, the main objectives of a control system consist on: i) maximizing the use of the available renewable energy source, thus minimizing the costs associated to the use of non-renewable sources, and ii) adapting the production to the demand, thus minimizing the operating costs of the electricity consuming devices as pumps. Regarding the first point, several control approaches have been presented in the literature as the ones presented in [7], [14], whereas only [15] deals with the second one. Although these works were not developed under an IoT framework, they can be easily extrapolated to be used in combination with the IoT technology, using approaches as the one presented in [19].

On the other hand, from greenhouses position, the control efforts are focused in the development of accurate irrigation control systems [10], [13]. Besides, some IoT based methods have been already proposed, as the one presented in [9], in which a smart water management method for precision irrigation was developed. These kind of works are in the line of the Precision Agriculture (PA) and smart farming, which are two relevant terms in the agriculture field. The first one is related to the use of Information and Communication Technology (ICT) tools that allow the optimization of resource 
management, through a network of sensors, actuators and other devices. The second term integrates the use of new technologies such as IoT, Big Data, cloud computing, artificial intelligence and deep learning in agricultural systems, which is known as the third green revolution [8].

The idea presented in this work consists on combining the IoT technology and advanced control strategies, in particular MPC controllers, to develop efficient methods to manage the combination of SMD plants and greenhouses. It should be taken into account that, in a real implementation of these kind of smart-grids, the normal situation is to have one or more SMD plants feeding a large number of greenhouses, which are usually geographically separated (tens of kilometers or more). To operate these smart-grids efficiently, a centralized control system is required, which must receive information from all the facilities and calculates the optimal operating points based on this information, following a determine criterion such as minimizing the operating costs. Thereby, the IoT technology is specially suitable for this application since it allows us to obtain interoperability between the different facilities regardless of their geographical location, as it is able to read from all the subsystems, to analyze all the data in the Cloud, and to send the corresponding control actions to the actuators of the facilities. In addition, one of the main advantages of the IoT technology is that it establishes interconnection between the devices through open standards to Cloud platform, unlike the typical architectures used nowadays in the industry as the Machine to Machine one, which permits remote connections between devices in a circuit or closed system.

Thus, in order to show the benefits that can be achieved, a case of study is proposed which combines several greenhouses connected to a SMD plant by means of a storage system. Moreover, the water public network is also considered for those cases in which the freshwater production of the SMD facility is not enough to fulfil the greenhouse requirements. Unlike the approaches presented until now in the literature, the MPC control system developed in this work has as main aim to minimize the operational costs, taking into account the associated electrical costs of the feed water SMD pumping system, and the costs of the water coming from the public utility network. The manipulated variables of the control system are: i) the number of MD modules in operation in the SMD facility, ii) the water coming from the SMD facility to the greenhouses, and iii) the water coming from the public network to the greenhouses. To make the decisions, the control system uses information coming from an IoT platform that unifies the information of the sensors and actuators of each of the agents (i.e. SMD plant, greenhouses and storage device) involved in the proposed smart-grid framework. Simulation results are presented to illustrate the benefits of the proposed approach.

\section{CASE OF STUDY}

The schematic diagram of the case of study adopted in this paper is presented in Fig. 1. As can be seen, it is composed by three greenhouses that can receive the required freshwater for irrigation from a SMD facility, by means of a buffer system, or from the public network. It should remarked that this is a simulation case of study based on the two real facilities described in the following subsections.

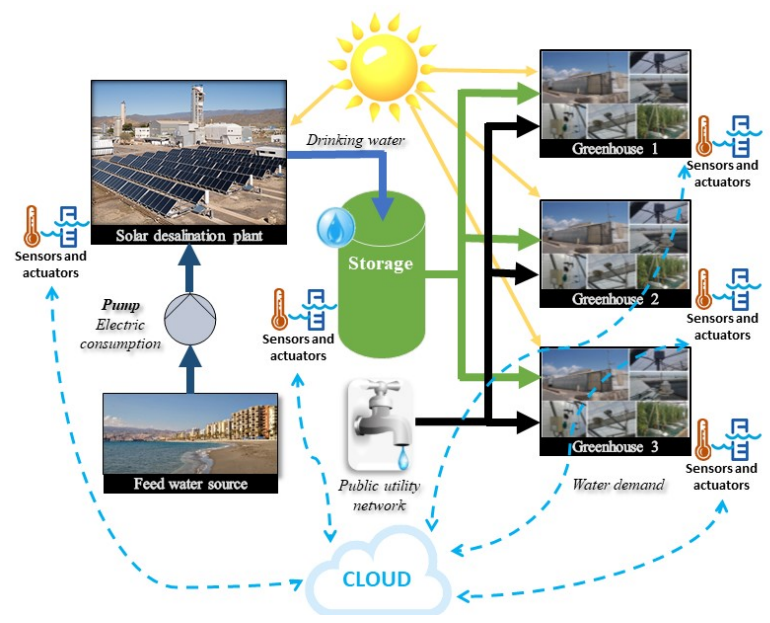

Fig. 1. Schematic diagram of the case of study.

\section{A. SMD facility}

The test bed SMD facility is located at the Plataforma Solar de Almería (Sutheast of Spain), and it was fully described in [20]. As can be observed in Fig. 2, it is composed by a solar thermal field connected with the MD modules through a storage tank and a heat exchanger. The plant is fully monitored and controlled, measuring the main variables involved in the distillation process as temperature, flow rate and pressure. Notice that for this work it is assumed that all the measurement and control devices are based on the IoT technology, and they can send and receive information directly to or from the cloud (see Fig. 1).

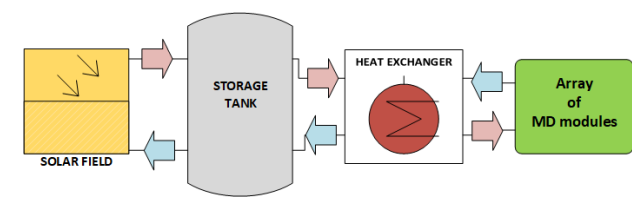

Fig. 2. Schematic diagram of the SMD facility.

There are several kind of commercial MD modules available in the actual facility, which can be classified according to their internal configuration. In this work, the Solar Spring module, which is based on the Air-Gap Membrane Distillation configuration, has been chosen owing to its high thermal efficiency and its high distillate production [17]. Due to the internal design of this module, there are some operational constraints in its operation. The temperature at the inlet of the evaporation channel of the module (see Fig. 3) must be in the range of $60-80{ }^{\circ} \mathrm{C}$, whereas the feed flow rate must be between 400 and $600 \mathrm{~L} / \mathrm{h}$. The maximum production of this kind of commercial MD module is around $30 \mathrm{~L} / \mathrm{h}$ [17], for this reason, an array of thirty MD modules is employed to fulfil the 
water requirements of the three greenhouses. The array of MD modules are connected in parallel, following the configuration showed in Fig. 3. It should be noted that each MD module can be turned on or off by using the available valves, thus allowing to adapt the SMD production to the water demand, and therefore, allowing to obtain economical savings in the operation of the feed water pump.

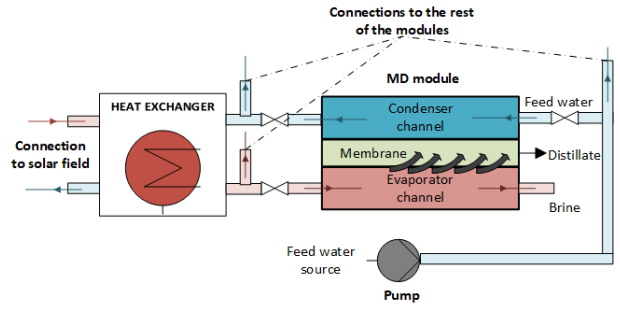

Fig. 3. Schematic diagram of the connection of a single module in the array.

\section{B. Greenhouse environment}

A multispam "Almería-type" greenhouse has been used as reference in this work for the three greenhouses, based on the one located in the Experimental Station of Cajamar Foundation, (Southeast of Spain, $40 \mathrm{~km}$ far from the Plataforma Solar de Almería). This greenhouse environment has an orientation E-W with a cover of polyethylene, and it is equipped with an automatic ventilation system with side windows on the walls north and south, LEDs lights, diesel aerothermal system, heating system fueled by biomass, and humidification and dehumidification system by condensation with a water extraction capacity of $900 \mathrm{~L} /$ day. The total surface area is $821 \mathrm{~m}^{2}$, among which, $616 \mathrm{~m}^{2}$ are used for cultivation. A more extended description of this environment was presented elsewhere [16].

As happens with the SMD facility, the greenhouse is fully monitored, measuring variables as relative humidity, PAR, $\mathrm{CO}_{2}$ concentration, air temperature, and solar radiation. It is also assumed that all the measurement and control devices are based on the IoT technology as in the case of the SMD facility (see Fig. 1).

\section{Connection between the SMD facility and the greenhouses}

The method to obtain the freshwater in the MD modules is based on an evaporation process. According to Fig. 3, the feed water passes through the condenser channel and it is lead to the heat exchanger, where it is heated with the fluid coming from the solar field. Finally, the heated solution circulates to the evaporation channel where the volatile molecules of the solution are evaporated and pass trough the membrane, while the nonvolatile molecules are rejected as brine. Finally, the evaporated solution is condensed obtaining as product distillate water. Therefore, it should be emphasised that the water produced in the SMD facility has a different composition than that of conventional water sources so it must be treated before using it for irrigation.

\section{THE IOT BASED CONTROL SYSTEM}

As mentioned in the introduction section, the IoT platform is used as a tool for obtaining interoperability between the different facilities included in the smart-grid, as they usually are in different locations. Thus, the control system uses the information related to the states of each facility, which is unified in the IoT platform, for deciding how many MD modules are connected in the array, and if the irrigation water required by the greenhouses comes from the SMD facility or from the public utility network. Notice that, it is assumed that when a MD module is turned on, it is run at its maximum feed flow rate $(600 \mathrm{~L} / \mathrm{h})$ since it is its optimal operating point [17]. It should be also commented that other kind of costs, as the costs associated to the operation of the solar field feeding the MD module array have not been considered, as they were already studied in the previous work [7]. In the same way, the amortization cost of the SMD facility has also not been taken into account, since it must be considered in algorithms aimed at making an optimal design of this kind plants, not in algorithms as the one proposed in this paper which is aimed at minimizing the operational costs.

\section{A. IoT platform}

The schematic diagram of the IoT platform is presented in Fig. 4. As can be seen, it is based on a client server architecture divided in front-end and back-end with the integration of IoT. Front-end is the data presentation layer and the backend the access one. As mentioned, each agent of the microgrid framework is equipped with a wireless sensors and actuators network (WSAN), known as the context generators [1], which are able to send information by means of different communication protocols (i.e. MQTT, OPC UA, HTTP) [18]. In this case, once the sensor generates the context information, it is sent to the IoT agent of Fiware (Agent in Fig. 4), which is in charge of traducing the information from Orion [11]. Orion has a fixed data structure for integrating all the data, which is based on the standard NGSIv2 [5]. The objective of this context broker is to integrate all the devices in only one platform. Once the information of each sensor and actuator is

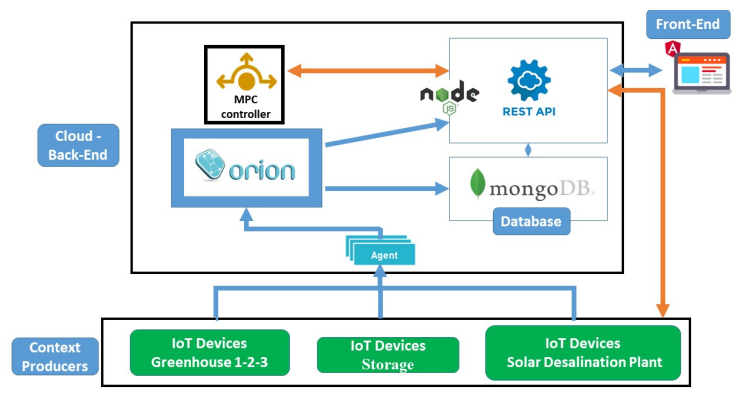

Fig. 4. Schematic diagram of the IoT platform.

available in Orion, subscriptions are made to each entity, which generate notifications to the REST API [12] notifying a change in the data, thus assuring the persistence of data. It should be commented that a non-relational database has been selected 
due to its flexibility in the data models and its scalability, which must be high because of the constant change that the IoT represents in the traditional data model. The MPC controller takes the required information for the optimization problem and solves it. Once the MPC controller obtains the optimal solutions, it sends it to the API Rest, which is responsible for persisting the new information. Finally, the optimal control actions are sent to the corresponding facility. Moreover, a web application is used to allow the user visualizing the states in real time of the facilities as well as the historical data.

\section{B. The MPC technique}

The control methodology adopted in this work is the MPC strategy as it is one of the most generic ways of formulating a control problem [4]. This strategy (see Fig. 5) is based on the use of a determined prediction horizon $N$, in which, the future outputs of the system, $\hat{\mathrm{y}}(\mathrm{t}+\mathrm{k} \mid \mathrm{t})^{*}$ for $\mathrm{k}=1 \ldots N$, are predicted using a model of the process. These predicted outputs depend on the information (past inputs and outputs of the system) known at instant $t$, and on the future control signals $u(t+k \mid t)$. The set of future inputs $(\mathrm{u}(\mathrm{t}+\mathrm{k} \mid \mathrm{t}))$ are obtained by formulating an optimization problem, which usually consists on keeping the output of the process $(\hat{\mathrm{y}}(\mathrm{t}+\mathrm{k} \mid \mathrm{t}))$ as close as possible of a desired reference trajectory. Finally, the control signal $u(t \mid t)$ is sent to the system whereas the rest of the control signals are rejected. Notice that this procedure is repeated in each sampling time, ts, with the new information available. Thus,

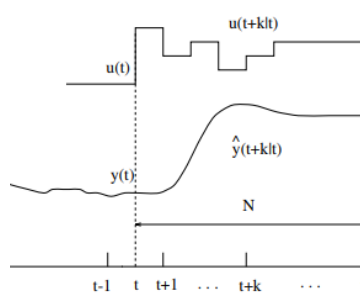

Fig. 5. MPC strategy [4].

the formulation of this technique for the proposed case of study is given by:

$$
\min J=\sum_{i=1}^{N}\left(\hat{\mathrm{C}_{\mathrm{PN}}}(\mathrm{t}+\mathrm{k} \mid \mathrm{t})+\hat{\mathrm{C}_{\mathrm{SMD}}}(\mathrm{t}+\mathrm{k} \mid \mathrm{t})\right),
$$

subjected to:

\footnotetext{
*The nomenclature $\hat{x}(\mathrm{t}+\mathrm{k} \mid \mathrm{t})$ means the estimation of the value of the variable $\mathrm{x}$ at the instant time $\mathrm{t}+\mathrm{k}$, calculated with the information acquired up in instant $\mathrm{t}$.
}

$$
\begin{array}{r}
\hat{\mathrm{SMD}_{\mathrm{P}}}=f\left(\mathrm{NMD}, \hat{\mathrm{T}_{\mathrm{he}}}, \hat{\mathrm{T}_{\mathrm{feed}}}\right), \\
\mathrm{NMD} \in\{0,1,2, \ldots, 30\}, \\
\hat{\mathrm{St}}=f\left(\mathrm{c} \cdot \mathrm{SMD}_{\mathrm{P}}, \mathrm{c} \cdot \mathrm{St} 2 \mathrm{GH} 1, \mathrm{c} \cdot \mathrm{St} 2 \mathrm{GH} 2, \mathrm{c} \cdot \mathrm{St} 2 \mathrm{GH} 3\right), \\
0 \leq \mathrm{SMD} \hat{\mathrm{P}} \leq 1500, \\
\hat{\mathrm{D}_{\mathrm{GH} 1}} \leq \mathrm{St} 2 \mathrm{GH} 1+\mathrm{PN} 2 \mathrm{GH} 1, \\
\mathrm{D}_{\mathrm{GH} 2} \leq \mathrm{St} 2 \mathrm{GH} 2+\mathrm{PN} 2 \mathrm{GH} 2, \\
\hat{\mathrm{D}_{\mathrm{GH}}} \leq \mathrm{St} 2 \mathrm{GH} 3+\mathrm{PN} 2 \mathrm{GH} 3, \\
\hat{\mathrm{P}_{\mathrm{PN}}}=f\left(\mathrm{PN} 2 \mathrm{GH} 1, \mathrm{PN} 2 \mathrm{GH} 2, \mathrm{PN} 2 \mathrm{GH} 3, \mathrm{~W}_{p}\right), \\
\mathrm{C}_{\mathrm{SMD}}=f\left(\mathrm{NMD}, \mathrm{E}_{p}\right) .
\end{array}
$$

On the one hand, the objective function, Eq. (1), is aimed at minimizing the costs of the operation, taking into account the cost of the water coming from the public network $\left(\hat{\mathrm{C}_{\mathrm{PN}}}(\mathrm{t}+\mathrm{k} \mid \mathrm{t})\right)$ and the ones of the feed pumping system of the SMD facility $\left(\mathrm{C}_{\mathrm{SMD}}(\mathrm{t}+\mathrm{k} \mid \mathrm{t})\right)$. On the other hand, Eqs. $(2-10)$ are the constraints of the optimization problem. It should be noted that in Eqs. (2-10) and hereinafter the nomenclature $(\mathrm{t}+\mathrm{k} \mid \mathrm{t})$ in all the variables has been omitted for the sake of simplicity.

The first constraint, Eq. (2), is related with the water production of the SMD facility, $\mathrm{SMD}_{\mathrm{P}}[\mathrm{L} / \mathrm{h}]$. This water production depends on the temperature at the output of the heat exchanger, $\hat{\mathrm{T}_{\mathrm{he}}}\left[{ }^{\circ} \mathrm{C}\right]$, the temperature of the feed water, $\mathrm{T}_{\text {feed }}\left[{ }^{\circ} \mathrm{C}\right]$, which is assumed constant in the horizon with a value of $20^{\circ} \mathrm{C}$ (mean value of Mediterranean sea), and the number of modules (NMD) in operation, which are run at $600 \mathrm{~L} / \mathrm{h}$ when they are turned on as was previously mentioned. Notice also that the feed water pump is regulated according to the requirements of the MD modules in operation. It should be also remarked that in a real implementation of this control problem $\hat{T_{\text {he }}}$ must be predicted with a model of the SMD facility, as was done in [7]. However, in this work real data are used as real facility and in the predictions. The second constraint, Eq. (3), limits the variable NMD to take integer values in the range $0-30$.

The third and fourth constraints, Eqs. (4-5), are associated to the storage level, $\hat{\mathrm{St}}[\mathrm{L}]$. The first one defines the state of the storage level, $\hat{\mathrm{St}}$, which depends on the water that receives from the SMD plant $\left(\mathrm{SMD}_{\mathrm{P}}\right)$, and the water that sends to greenhouses 1, 2 and 3 (St2GH1, St2GH2, St2GH3 in [L/h]). Notice that $\mathrm{c}$ is a constant for unit conversion (from $\mathrm{L} / \mathrm{h}$ to $\mathrm{L}$ ). The second one, Eq. (5), limits the water volume to the size of the storage.

Eqs. (6-8) are related with the water demand of each of the greenhouses, which must be always satisfied by the sum of the water that each greenhouse receives from the storage tank and from the public network. $\hat{\mathrm{D}_{\mathrm{GH} 1}}, \hat{\mathrm{D}_{\mathrm{GH}} 2}$, and $\hat{\mathrm{D}_{\mathrm{GH} 3}}$ are the demands in $[\mathrm{L} / \mathrm{h}]$ of greenhouse 1, 2 and 3 respectively. As happens previously, in a real application, these demands must be estimated by using a model of the greenhouse as the one presented in [16], in this work real data has been used as real facility and for predictions. PN2GH1, PN2GH2, and $\mathrm{PN} 2 \mathrm{GH} 13$, in $[\mathrm{L} / \mathrm{h}]$, are the variables associated with 
the water that greenhouse 1,2 and 3 receive from the public network.

Finally, Eqs. (9-10) defines the costs. The cost of the water coming from the public utility network, $\hat{\mathrm{C}_{\mathrm{PN}}}$, is a function of the water that each greenhouse receive from this source (PN2GH1, PN2GH2, and PN2GH3) and of the water price $\left(\mathrm{W}_{\mathrm{p}}\right)$. The costs associated with the electrical energy consumed by the feed SMD pump, $\mathrm{C}_{\mathrm{SMD}}$, which can be easily calculated with the curves provided by manufactures, is a function of the number of MD modules in operation (NMD) and of the electricity price, $\mathrm{E}_{\mathrm{p}}$.

Notice that the set of constraints Eqs. (2-10) defines the physical relations between the agents involved in the optimization problem as well as their physical limits. Nevertheless, apart from these constraints, there is an operational constraint that must be taken into consideration. As mentioned in section II.A, the MD modules only can be turned on when $\mathrm{T}_{\text {he }}$ is greater or equal than $60\left[{ }^{\circ} \mathrm{C}\right]$. To introduce this statement to the problem the following constraints have been added:

$$
\begin{array}{r}
-m \cdot \delta \leq\left(\hat{\mathrm{T}_{\mathrm{he}}}-\mathrm{T}^{*}\right)-m, \\
-M \cdot \delta \leq-\left(\hat{\mathrm{T}_{\mathrm{he}}}-\mathrm{T}^{*}\right), \\
\delta \in\{0,1\} .
\end{array}
$$

In this way, Eq. (11) and Eq. (12) are in charge of turning on or off a binary variable $\delta$, whether $\mathrm{T}_{\text {he }}$ is greater or equal than a reference temperature $\mathrm{T}^{*}$ or not, which is equal to $60\left[{ }^{\circ} \mathrm{C}\right]$ in this case. $\mathrm{M}$ and $\mathrm{m}$ are two constants that can be defined as the maximum and minimum difference between $\hat{\mathrm{T}_{\mathrm{he}}}$ and $\mathrm{T}^{*}$. If these differences are not known, $\mathrm{M}$ can be defined as a larger number, i.e 1000, and $\mathrm{m}$ as a large negative number, i.e. -1000 (which are the values employed in this work).

Now, a relation between the variable $\delta$ and the variable NMD must be defined. If $\delta$ is equal to 0 , NMD must be equal to 0 . Conversely, if $\delta$ is equal to 1 , NMD can take any value in $\{0,1, \ldots, 30\}$. This relation can be defined in a simple way as the multiplication between the two variables, $\delta$.NMD. However, this multiplication would add a nonlinear term in the optimization problem, which has been formulated as linear one. To avoid this nonlinear term, a new continuos variable $z$ equivalent to the multiplication $\delta \cdot \mathrm{NMD}$ has been employed following the procedure presented in [2]:

$$
\begin{aligned}
& \mathrm{NMD}_{\text {min }} \leq \mathrm{NMD} \leq \mathrm{NMD}_{\max }, \\
& \mathrm{NMD}_{\text {min }} \cdot d \leq z \leq \delta \cdot \mathrm{NMD}_{\text {max }}, \\
& \mathrm{NMD}-\left(\mathrm{NMD}_{\max }\right) \cdot(1-\delta) \leq z \leq \mathrm{NMD}-\mathrm{NMD}_{\min } \cdot(1-\delta),
\end{aligned}
$$

where $\mathrm{NMD}_{\max }$ is the maximum value of the variable NMD, which is 30 , and $\mathrm{NMD}_{\min }$ its minimum value, which is 0 . Notice that the variable $z$ has to be replaced by the variable NMD in Eq. (2) and Eq. (10).

Once the whole optimization problem has been defined, it should be remarked that the decision variables are $\delta$, NMD, St2GH1, St2GH2, St2GH3, PN2GH1, PN2GH2, and

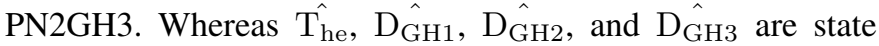
variables that depends on the operational conditions of the SMD facility and the greehouses respectively.

\section{RESUlts}

The control strategy has been tested in simulation, using Matlab 2018b with YALMIP toolbox and CPLEX solver. Real meteorological data from Experimental Station of Cajamar Foundation and from Plataforma Solar de Almería on the day July 20, 2017 have been employed. The models of the SMD facility and the one of the greenhouse have been simulated to obtain the profile of the temperature $T_{\text {he }}$ and the water requirements of the greenhouses respectively. In order to add complexity to the problem, different sizes in the greenhouses have been imposed. Thus, the greenhouse 1 and 2 have a size of 1 ha, while the greenhouse 3 has a size of 0.5 ha. Besides, two days have been simulated replicating the meteorological data but increasing the irradiance in the second day in greenhouses 2 and 3 in order to increase their water demand. In addition, the irradiance profile for the case of greenhouse 3 has been shifted on the time $15 \mathrm{~min}$.

The tuning parameters of the controller are: i) sampling time (ts) equal to $10 \mathrm{~min}$, selected taking into consideration the dynamics of greenhouses and SMD facility, and ii) prediction horizon $(N)$ equal to 12 . It should be remarked that the prediction horizon must be large enough to capture the transients presented in the process.

The simulation results are shown in Fig. 6. It should be remarked that the costs associated to the operation of the feed pump of the SMD facility are lower that the ones of the water coming from the public utility network, even in the case in which all the modules are turned on. Thus the optimal solution of the problem is that the greenhouses must be fed by the SMD plant whenever possible, and therefore, at the end of the day, the level of the storage system must be zero or close to zero. For this reason, at the beginning of the test, the water level of the storage tank is set a $50 \mathrm{~L}$.

Thus, around sample 36, greenhouses 1 and 2 begin demanding water (see Fig. $6(3,4)$ ). As the temperature $T_{\text {he }}$ is below $\mathrm{T}^{*}$ (see Fig. 6 (2)), the SMD facility cannot produce freshwater yet. In this way, the greenhouses take the remaining water of the storage tank and water from the public network to meet their requirements (observe Fig. $6(1,3,4)$ ). Then, at sample $38, \mathrm{~T}_{\mathrm{he}}$ reaches $\mathrm{T}^{*}$, and the SMD facility starts producing. Notice that in this sample time also the greenhouse 3 starts demanding water (see Fig. 6 (5)). During the rest of the operation in this day, the irrigation water requirements of the greenhouses are satisfied by the SMD plant. It should be remarked how the controller tries to keep the minimum number of modules in operation satisfying the water requirements and avoiding the use of the public utility network. The advantage of using a predictive controller can be specially observed at the end of the day. In this moment, and before $\mathrm{T}_{\text {he }}$ reaching $\mathrm{T}^{*}$, the controller augments the number of modules in operation (see around sample 80 in Fig. 6 (2)) in order to increase the water stored in the tank to avoid using water from the public network when all the MD modules are turned off.

In the second day, and as happened in the previous one, greenhouses 2 and 3 start demanding water before the MD 


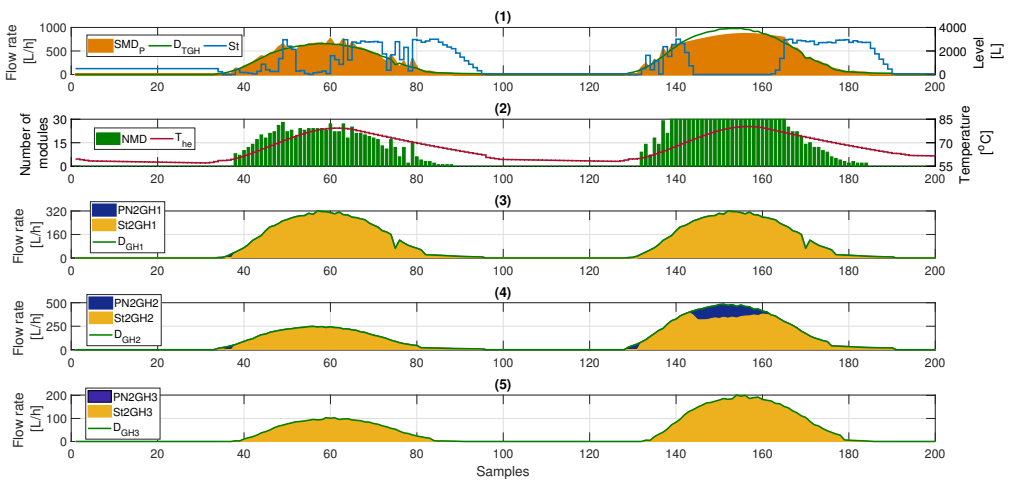

Fig. 6. Simulation results. $\mathrm{D}_{\mathrm{TGH}}$ is the total water demand of the three greenhouses, and $\mathrm{SMD}_{\mathrm{p}}$ is the SMD fresh water production. The rest of variables have been previously defined.

modules are turned on. However, in this case, there is no water in the storage tank (see Fig. 6 (1)), so they use water coming from the public network. As can be seen in Fig. 6 (3, 4) the water demand of greenhouses 2 and 3 is higher that in the previous day. This fact causes that the controller turns on all the available MD modules. Nevertheless, the water produced by them is not enough to meet the irrigation water requirements, for this reason, it should be complemented with water coming from the public network which is sent to greenhouse 2 (see Fig. 6 (4) between samples 145-163). At the end of the operation happens the same fact than in the previous day, the water stored in the tank is increased to fulfil the water requirements of the greenhouses when the SMD plant is turned off.

\section{CONCLUSIONS AND FUTURE WORKS}

This work has addressed the development of a model predictive control strategy to be used in combination with an IoT platform for the optimal management of a smart grid framework. The smart-grid is composed by a Solar Membrane Distillation Facility and some greenhouses connected through a storage tank, in addition, the use of the water public utility network is also contemplated. Simulation results have been presented showing the high performance of the controller.

Future works will be focused in the proper development of the IoT solution.

\section{REFERENCES}

[1] V. I. Adamchuk, J. Hummel, M. Morgan, and S. Upadhyaya, "On-thego soil sensors for precision agriculture," Computers and electronics in agriculture, vol. 44, no. 1, pp. 71-91, 2004.

[2] A. Bemporad and M. Morari, "Control of systems integrating logic, dynamics, and constraints," Automatica, vol. 35, no. 3, pp. 407-427, 1999.

[3] S. Burn, M. Hoang, D. Zarzo, F. Olewniak, E. Campos, B. Bolto, and O. Barron, "Desalination techniques-A review of the opportunities for desalination in agriculture," Desalination, vol. 364, pp. 2-16, 2015.

[4] E. Camacho and C. Bordons, Model Predictive Control. London: Springer-Verlag Ltd, 2004.

[5] M. Fazio, A. Celesti, F. G. Marquez, A. Glikson, and M. Villari, "Exploiting the FIWARE cloud platform to develop a remote patient monitoring system," in 2015 IEEE Symposium on Computers and Communication (ISCC). IEEE, 2015, pp. 264-270.
[6] P. Garcia-Caparros, J. I. Contreras, R. Baeza, M. L. Segura, and M. T. Lao, "Integral management of irrigation water in intensive horticultural systems of Almería," Sustainability, vol. 9, no. 12, p. 2271, 2017.

[7] J. D. Gil, L. Roca, A. Ruiz-Aguirre, G. Zaragoza, and M. Berenguel, "Optimal operation of a solar membrane distillation pilot plant via nonlinear model predictive control," Computers \& Chemical Engineering, vol. 109, pp. 151-165, 2018.

[8] G. Gomes and A. Pérez García, "El proceso de modernización de la agricultura latinoamericana," 1979.

[9] C. Kamienski, J.-P. Soininen, M. Taumberger, S. Fernandes, A. Toscano, T. S. Cinotti, R. F. Maia, and A. T. Neto, "Swamp: an iot-based smart water management platform for precision irrigation in agriculture," in 2018 Global Internet of Things Summit (GIoTS). IEEE, 2018, pp. 1-6.

[10] C. Lozoya, C. Mendoza, A. Aguilar, A. Román, and R. Castelló, "Sensor-based model driven control strategy for precision irrigation," Journal of Sensors, vol. 2016, 2016.

[11] B. Moltchanov and O. R. Rocha, "A context broker to enable future IoT applications and services," in 2014 6th International Congress on Ultra Modern Telecommunications and Control Systems and Workshops (ICUMT). IEEE, 2014, pp. 263-268.

[12] S. P. Ong, S. Cholia, A. Jain, M. Brafman, D. Gunter, G. Ceder, and K. A. Persson, "The materials application programming interface (API): A simple, flexible and efficient api for materials data based on representational state transfer (REST) principles," Computational Materials Science, vol. 97, pp. 209-215, 2015.

[13] A. Pawlowski, J. Sánchez-Molina, J. Guzmán, F. Rodríguez, and S. Dormido, "Evaluation of event-based irrigation system control scheme for tomato crops in greenhouses," Agricultural Water Management, vol. 183 , pp. 16-25, 2017.

[14] R. Porrazzo, A. Cipollina, M. Galluzzo, and G. Micale, "A neural network-based optimizing control system for a seawater-desalination solar-powered membrane distillation unit," Computers \& Chemical Engineering, vol. 54, pp. 79-96, 2013.

[15] L. Roca, J. A. Sánchez, F. Rodríguez, J. Bonilla, A. de la Calle, and M. Berenguel, "Predictive control applied to a solar desalination plant connected to a greenhouse with daily variation of irrigation water demand," Energies, vol. 9, no. 3, p. 194, 2016.

[16] F. Rodríguez, M. Berenguel, J. L. Guzmán, and A. Ramírez-Arias, Modeling and control of greenhouse crop growth. Springer, 2015.

[17] A. Ruiz-Aguirre, J. Andrés-Mañas, J. Fernández-Sevilla, and G. Zaragoza, "Modeling and optimization of a commercial permeate gap spiral wound membrane distillation module for seawater desalination," Desalination, vol. 419, pp. 160-168, 2017.

[18] D. C. Y. Vargas and C. E. P. Salvador, "Smart IoT gateway for heterogeneous devices interoperability," IEEE Latin America Transactions, vol. 14, no. 8, pp. 3900-3906, 2016.

[19] U. Yaqub, A. Al-Nasser, and T. Sheltami, "Implementation of a hybrid wind-solar desalination plant from an internet of things (IoT) perspective on a network simulation tool," Applied computing and informatics, 2018.

[20] G. Zaragoza, A. Ruiz-Aguirre, and E. Guillén-Burrieza, "Efficiency in the use of solar thermal energy of small membrane desalination systems for decentralized water production," Applied Energy, vol. 130, pp. 491499, 2014. 

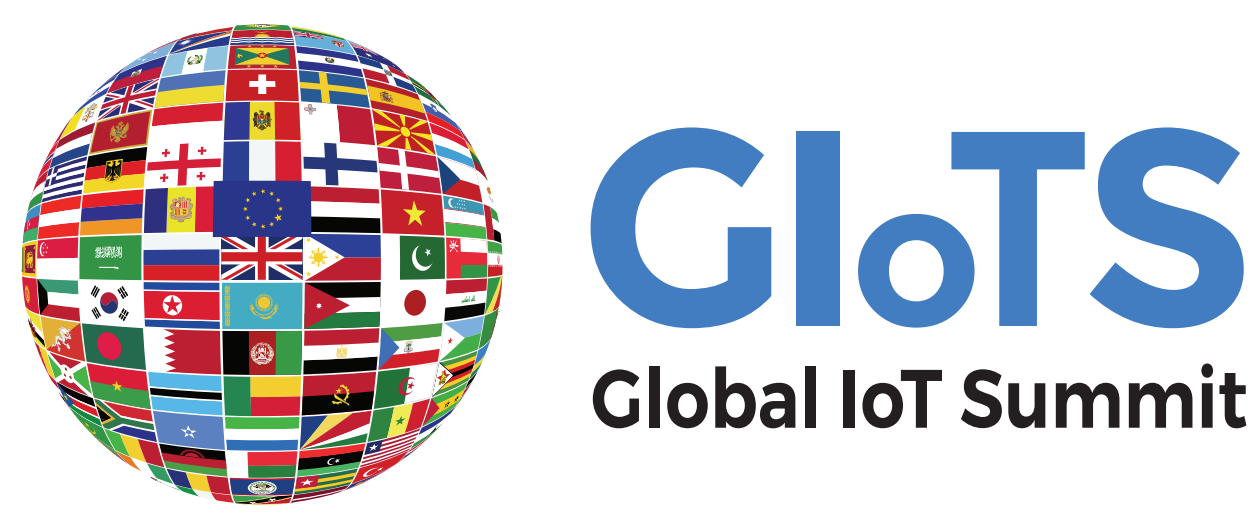

\section{Global loT Summit}

\section{Aarhus 17-21 June 2019}

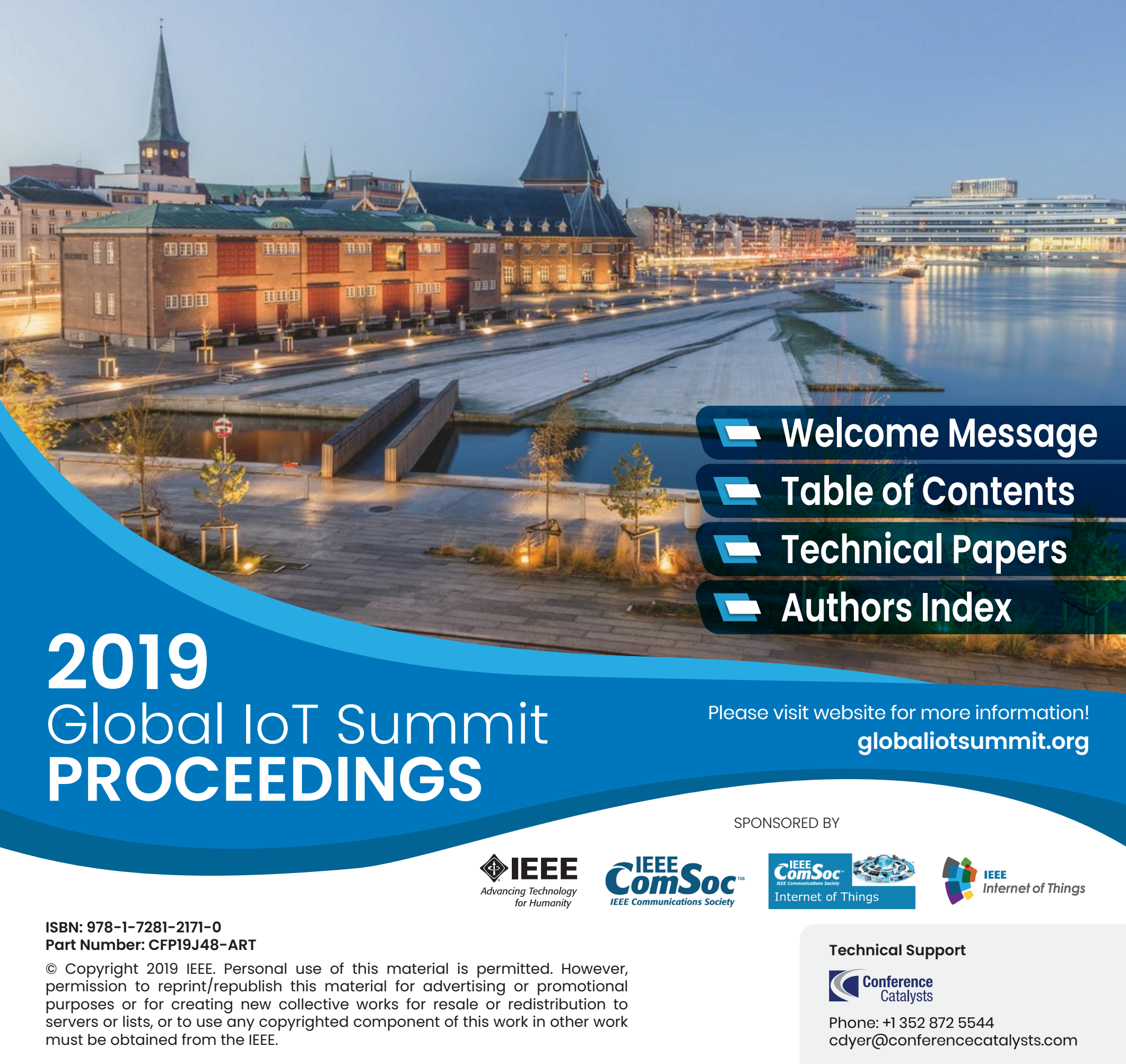




\section{IEEE Global Internet of Things Summit (GloTS) Proceedings}

(C) 2019 IEEE. Personal use of this material is permitted. However, permission to reprint/republish this material for advertising or promotional purposes or for creating new collective works for resale or redistribution to servers or lists, or to reuse any copyrighted component of this work in other works must be obtained from the IEEE.

Additional copies may be ordered from:

IEEE Service Center

445 Hoes Lane

Piscataway, NJ 08855-1331 USA

+1800678 IEEE (+1 800678 4333)

$+17329811393$

+17329819667 (FAX)

Email: customer-service@ieee.org

Copyright and Reprint Permission: Abstracting is permitted with credit to the source. Libraries are permitted to photocopy beyond the limit of U.S. copyright law for private use of patrons those articles in this volume that carry a code at the bottom of the first page, provided the per-copy fee indicated in the code is paid through Copyright Clearance Center, 222 Rosewood Drive, Danvers, MA 01923. For reprint or republication permission, email to IEEE Copyrights Manager at pubspermissions@ieee.org. All rights reserved. Copyright @2019 by IEEE.

Part Number: CFP19J48-ART

ISBN: 978-1-7281-2171-0 


\section{Table of Contents}

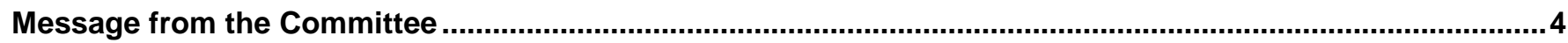

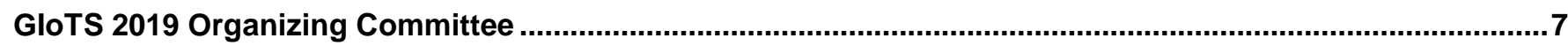

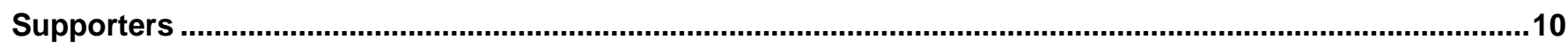

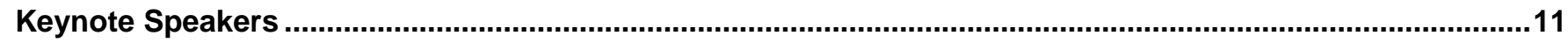

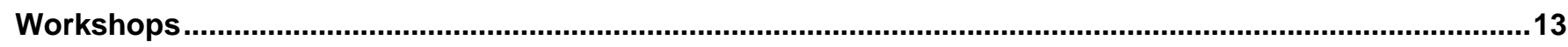

3rd Workshop on Future Internet Model for Smart City Services ...............................................................13

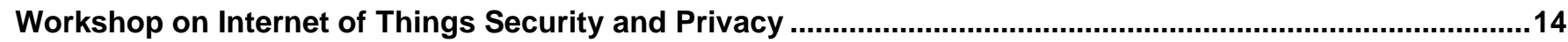

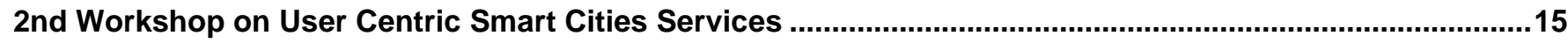

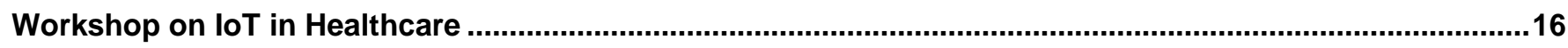

Workshop on Business Model Innovation and Sustainability in IoT (BMIS-loT),..........................................18

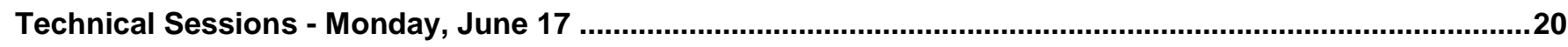

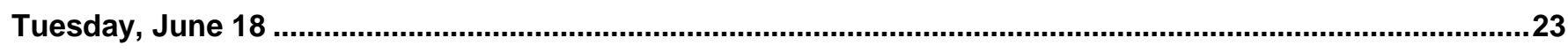

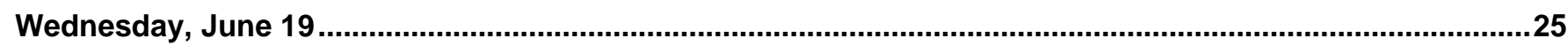

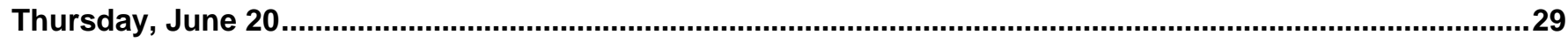

Author Index 


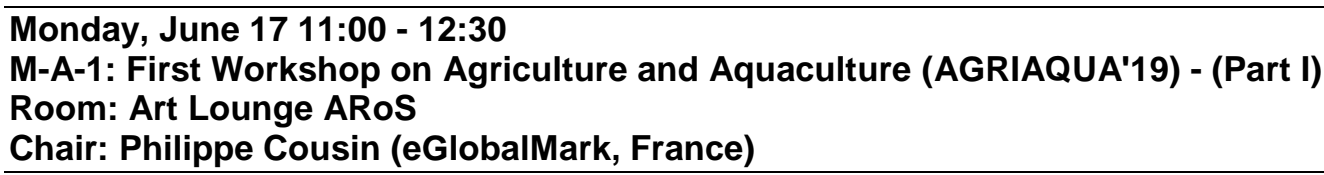

Secure smart agriculture monitoring technique through isolation

Cristiana-Ioana Istrate (BEIA Consult International \& University Politehnica of Bucharest, Romania); George Suciu

(Politehnica University of Bucharest \& BEIA Consult International SRL, Romania); Maria Ditu (BEIA Consult International

\& University Politehnica of Bucharest, Romania)

Analysis of the variables that affect the intention to adopt Precision Agriculture for smart water management in Agriculture 4.0 context

Sergio Monteleone (Centro Universitário da FEl, Brazil); Rodrigo Filev Maia (Centro Universitario FEI, Brazil); Edmilson A Moraes (FEI University, Brazil)

Water Management: Agricolus tools integration

Susanna Marchi, Diego Guidotti, Sara Antognelli and Andrea Cruciani (Agricolus srl, Italy)

\title{
M-L-1: Workshop on Business Model Innovation and Sustainability in loT (BMIS-IoT) \\ Room: Sunset Lounge ARoS \\ Chair: Mirko Alexander Presser (Aarhus University, Denmark)
}

Applying loT as a leverage for business model innovation and digital transformation

Annabeth Aagaard, Mirko Alexander Presser and Troels Andersen (Aarhus University, Denmark)

EDUMONDO: Prototyping a Learning Analytics System

Rasmus Præstegaard, Daniel Wiencken, Tom Collins and Mirko Alexander Presser (Aarhus University, Denmark)

Internet of Things for a sustainable food packaging ecosystem insights from a business perspective Michail Beliatis, Nipaporn Lohacharoenvanich, Annabeth Aagaard and Mirko Alexander Presser (Aarhus University, Denmark)

IoT Driven Business Model Innovation and Sustainability: a literature review and a case Study in Brazil Cesar Alexandre Souza (University of São Paulo, Brazil); Annabeth Aagaard and Mirko Alexander Presser (Aarhus University, Denmark); Juliana Nelia Nascimento Correa (University of São Paulo, Brazil); Moacir Oliveira jr (University of são paulo, Brazil)

\author{
Monday, June 17 2:00 - 3:30 \\ M-A-2: First Workshop on Agriculture and Aquaculture (AGRIAQUA'19) - (Part II) \\ Room: Art Lounge ARoS \\ Chair: Philippe Cousin (eGlobalMark, France)
}

An loT based Control System for a Solar Membrane Distillation Plant used for Greenhouse Irrigation Juan Diego Gil (Universidad de Almería, Spain); Manuel Muñoz Rodriguez (University of Almeria, Spain); Lidia Roca (CIEMAT-PSA, Spain); Francisco F Rodriguez-Diaz (University of Almeria, Spain); Manuel Berenguel (Universidad de Almeria \& Ctra. Sacramento $\mathrm{s} / \mathrm{n}$, Spain)

IoT and data interoperability in agriculture: A case study on the gaiasense smart farming solution Nikos Kalatzis, Nikolaos Marianos and Fotis Chatzipapadopoulos (Neuropublic S.A., Greece) 